\title{
recildunds
}

Revista Cientifica Mundo de la Investigación y el Conocimiento

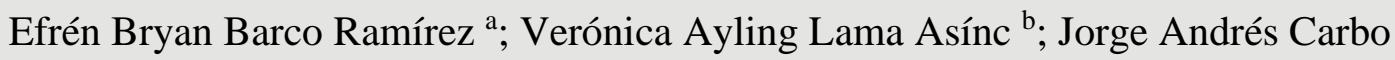

Palacio ${ }^{c}$; Freddy Leónidas Monge Paladines ${ }^{\mathrm{d}}$

Síndrome de McCune-Albright: multiples fracturas patologicas en paciente con menarquia precoz

McCune-Albright syndrome: multiple pathological fractures in patients with early menarche

Revista Científica Mundo de la Investigación y el Conocimiento. Vol. 3 núm. 4., diciembre, ISSN: 2588-073X, 2019, pp. 586-605

DOI: $10.26820 /$ recimundo/3.(4).diciembre.2019.586-605

URL: http://recimundo.com/index.php/es/article/view/683

Código UNESCO: 3205 Medicina Interna

Tipo de Investigación: Artículo de Revisión

(C) RECIMUNDO; Editorial Saberes del Conocimiento, 2019

Recibido: 15/09/2019

Aceptado: 23/11/2019

Publicado: 30/12/2019

Correspondencia: marthica12@msn.com

a. Médico; Investigador Independiente; Guayaquil, Ecuador; Efrenbarcoramirez@ outlook.es

b. Médico; Investigador Independiente; Guayaquil, Ecuador; aylinglamaasinc@gmail.com

c. Médico; Investigador Independiente; Guayaquil, Ecuador; jcarbop91@ gmail.com

d. Médico; Investigador Independiente; Guayaquil, Ecuador; fmongepaladines_91@yahoo.com 


\section{Síndrome de McCune-Albright: multiples fracturas patologicas en paciente \\ con menarquia precoz}

Vol. 3, núm. 4., (2019)

Efrén Bryan Barco Ramírez; Verónica Ayling Lama Asínc; Jorge Andrés Carbo Palacio; Freddy

Leónidas Monge Paladines

\section{RESUMEN}

El síndrome de McCune-Albright, es una entidad genética no hereditaria y poco frecuente que corresponde a trastorno postzigótico producido por una mutación somática en el gen GNAS 1. La incidencia mundial es desconocida, pero se estima una frecuencia de un caso por cien mil a un caso por millón de habitantes, esta entidad suele componerse clásicamente por displasia fibrótica poliostótica, manchas café con leche y alteraciones endocrinas; de esta ultima la principal es la pubertad precoz que puede debutar con una menarquia precoz, sin embargo, se pueden asociar otras endocrinopatías. El diagnostico puede estar basado en la clínica cuando se tienen dos de los tres componentes clásicos del síndrome, sin embargo, se pueden requerir de estudios endocrinos completos, pruebas de imágenes, histopatología y estudios genéticos cuando no se manifiesta de manera clásica. El tratamiento para el síndrome de McCune-Albright no es especifico, puede incluir fármacos que controlen las manifestaciones endocrinas, intervenciones quirúrgicas para las endocrinopatías o fracturas derivadas de la displasia fibrosa poliostótica.

Palabras Claves: Displasia Fibrótica Poliostótica; Manchas Café con Leche; Síndrome de Mccune-Albright; Menarquia Precoz. 


\section{Síndrome de McCune-Albright: multiples fracturas patologicas en paciente con menarquia precoz}

Vol. 3, núm. 4., (2019)

Efrén Bryan Barco Ramírez; Verónica Ayling Lama Asínc; Jorge Andrés Carbo Palacio; Freddy Leónidas Monge Paladines

\section{ABSTRACT}

The McCune-Albright syndrome is a non-hereditary and rare genetic entity that corresponds to a postzigotic disorder produced by a somatic mutation in the GNAS 1 gene. The global incidence is unknown, but it's estimated a frequency of one case per hundred thousand to one case per million inhabitants, this entity is usually composed by polyostotic fibrotic dysplasia, café-au-lait spots and endocrine alterations; of the latter the main one is precocious puberty that can debut with precocious menarche, however other endocrinopathies can be associated. The diagnosis can be based on clinic when two of the three classic components of the syndrome are present, however, complete endocrine studies, imaging tests and genetic studies may be required when the disease doesn't have a classical presentation. Treatment for McCune-Albright syndrome is not specific, this may include drugs that control endocrine manifestations, surgical interventions for endocrinopathies or fractures derived from polyostotic fibrous dysplasia.

Keywords: Polyostotic Fibrotic Dysplasia; Café-Au-Lait Spots; Mccune-Albright Syndrome; Early Menarche. 


\section{Síndrome de McCune-Albright: multiples fracturas patologicas en paciente \\ con menarquia precoz}

Vol. 3, núm. 4., (2019)

Efrén Bryan Barco Ramírez; Verónica Ayling Lama Asínc; Jorge Andrés Carbo Palacio; Freddy

Leónidas Monge Paladines

\section{Introducción.}

El síndrome de McCune-Albright constituye una entidad poco común cuya exacta incidencia mundial es desconocida y en nuestro país la incidencia estimada y exacta es también desconocida. La clínica puede incluir los componentes clásicos que caracterizan a este síndrome como son la displasia fibrosa poliostótica, pigmentación de la piel bajo la forma de manchas café con leche y pubertad precoz; en este caso el diagnóstico puede ser sospechado. La expresión clínica depende de la cantidad de células mutadas y órganos afectados, debido a esto no siempre está presente la tríada clásica y el diagnóstico puede ser difícil, pudiendo así, ser infradiagnosticado.

\section{Presentación de caso}

Paciente femenino de 28 años, etnia mestiza de la provincia del Guayas que acudió en enero del 2016 al IESS sur (Valdivia)

APP: menarquia a los 2 años de edad( se trato con danazol 400mg/dia) prolapso mitra fractura patológica de fémur a la edad de 17 años la cual fue tratada mediante curetaje.

APF: no refiere patologias de importancia paciente acude en enero del 2016 al IESS sur valdivia por presentar claudicación de la marcha y dolor a nivel de aductores derechos de 1 mes de evolución el mismo que exacerbaba al realizar maniobra de aducción contra resistencia.

\section{Exploración física}

- Signos vitales: TA 140/80 mmhg FC: 78 lpm FR: 21 T 36.5 ${ }^{\mathrm{a}} . \mathrm{C}$ 
Síndrome de McCune-Albright: multiples fracturas patologicas en paciente con menarquia precoz

Vol. 3, núm. 4., (2019)

Efrén Bryan Barco Ramírez; Verónica Ayling Lama Asínc; Jorge Andrés Carbo Palacio; Freddy Leónidas Monge Paladines

- Cara y craneo: asimetría facial, dolor que exacerbaba a la palpación de la articulación temporomaxilar y durante la masticación.

- Oftalmologica: hiporreflexia pupilar leve del ojo izquierdo y defecto pupilar aferente del mismo ojo

- Cuello: simetrico

- Torax: simetrico

- Abdomen: blando con dolor en la palpacion profunda

- El resto de la exploracion fisica sin alteraciones

Laboratorio

- Leucocitos (wbc): 7.75ul

- Hemoglobina (hgb): $12.6 \mathrm{~g} / \mathrm{dl}$

- Hematocrito (hct): $38.7 \mathrm{ml} / \mathrm{dl}$

- Volumen corp. medio (mcv): $86.6 \mathrm{fl}$

- Conc.media hemog. (mch): $28.2 \mathrm{~g} / \mathrm{dl}$

- Conc.corp.media (mchc) de hemo: $32.6 \mathrm{~g} / \mathrm{dl}$

- Glucosa: $91 \mathrm{mg} / \mathrm{dl}$

- Urea: $23 \mathrm{mg} / \mathrm{dl}$

- Creatinina: $0.62 \mathrm{mg} / \mathrm{dl}$

- Trigliceridos: $398 \mathrm{mg} / \mathrm{dl}$

- Colesterol: $293 \mathrm{mg} / \mathrm{dl}$ 


\section{Síndrome de McCune-Albright: multiples fracturas patologicas en paciente con menarquia precoz}

Vol. 3, núm. 4., (2019)

Efrén Bryan Barco Ramírez; Verónica Ayling Lama Asínc; Jorge Andrés Carbo Palacio; Freddy

Leónidas Monge Paladines

- Calcio total: $8.80 \mathrm{mg} / \mathrm{dl}$

- IGf-1.: $111.00(\mathrm{U} / \mathrm{ml})$

- Lh hormona luteinizante.: $1.96 \mathrm{mUU} / \mathrm{ml}$

- 17-beta estradiol.: $904.60 \mathrm{pg} / \mathrm{ml}$

- Parathormona: $20.90 \mathrm{pg} / \mathrm{ml}$

Estudios imagenológicos

- Pelvis ósea:

Imágenes oseas endomedulares predominantemente líticas que comprometen también ambos fémures particularmente cabezas y epífisis proximales. las lesiones expanden la cortical ósea adelgazándola sin destrucción de la misma.

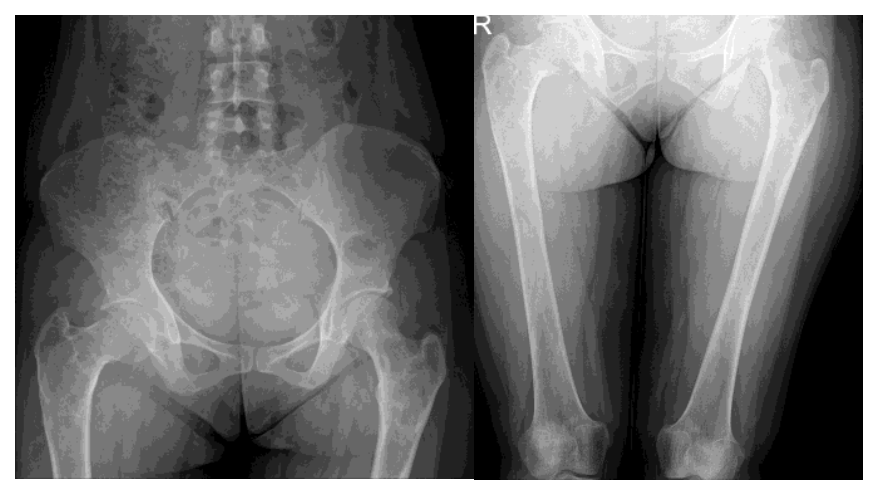

- Columna dorso lumbar:

Cifosis dorsal levemente pronunciada, discreta rotoescoliosis dorso lumbar. 
Síndrome de McCune-Albright: multiples fracturas patologicas en paciente con menarquia precoz

Vol. 3, núm. 4., (2019)

Efrén Bryan Barco Ramírez; Verónica Ayling Lama Asínc; Jorge Andrés Carbo Palacio; Freddy Leónidas Monge Paladines

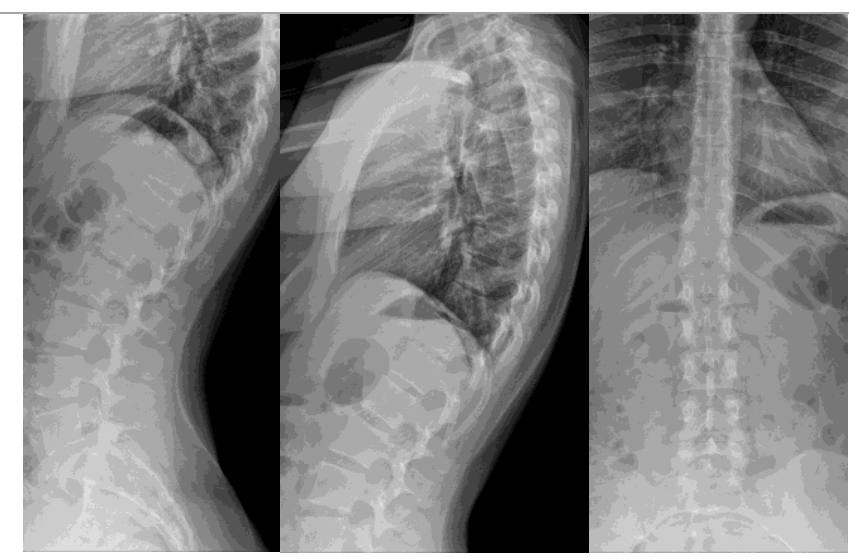

- Humero cubito y radio:

Se observan múltiples imágenes oseas endomedulares predominantemente líticas que comprometen tercio distal de humero, tercio proximal y medial del radio, además de observarse fractura consolidada en tercio proximal del mismo, las lesiones expanden la cortical ósea adelgazándola sin destrucción de la misma

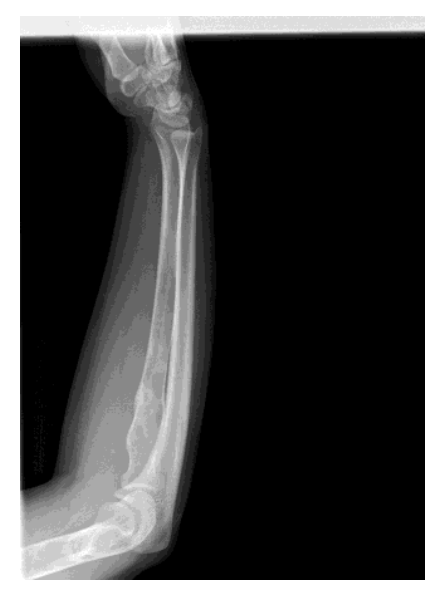

- Radiografía de edad ósea

Radiografía de edad ósea no dominante: 


\section{Síndrome de McCune-Albright: multiples fracturas patologicas en paciente con menarquia precoz}

Vol. 3, núm. 4., (2019) Efrén Bryan Barco Ramírez; Verónica Ayling Lama Asínc; Jorge Andrés Carbo Palacio; Freddy Leónidas Monge Paladines

Según el método de Greulich-Pyle en base a la maduración de huesos y muñeca, la edad ósea corresponde a mayor de 18 años.

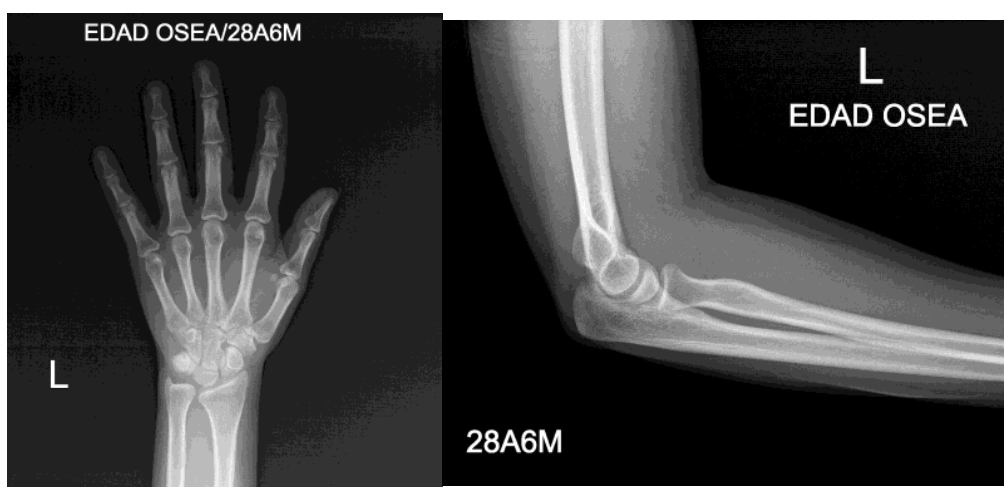

\section{Tomografía cabeza}

- Articulación temporomandibular:

Presenta canino superior izquierdo retenido por odontoma.

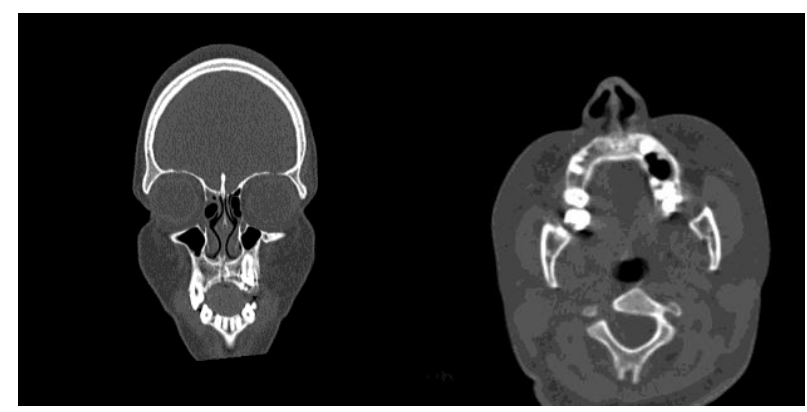

- Tomografía abdominal

En ventana ósea se aprecian imágenes líticas en L3, L4 y L5; y a nivel de crestas iliacas y femorales. 
Síndrome de McCune-Albright: multiples fracturas patologicas en paciente con menarquia precoz

Vol. 3, núm. 4., (2019)

Efrén Bryan Barco Ramírez; Verónica Ayling Lama Asínc; Jorge Andrés Carbo Palacio; Freddy Leónidas Monge Paladines

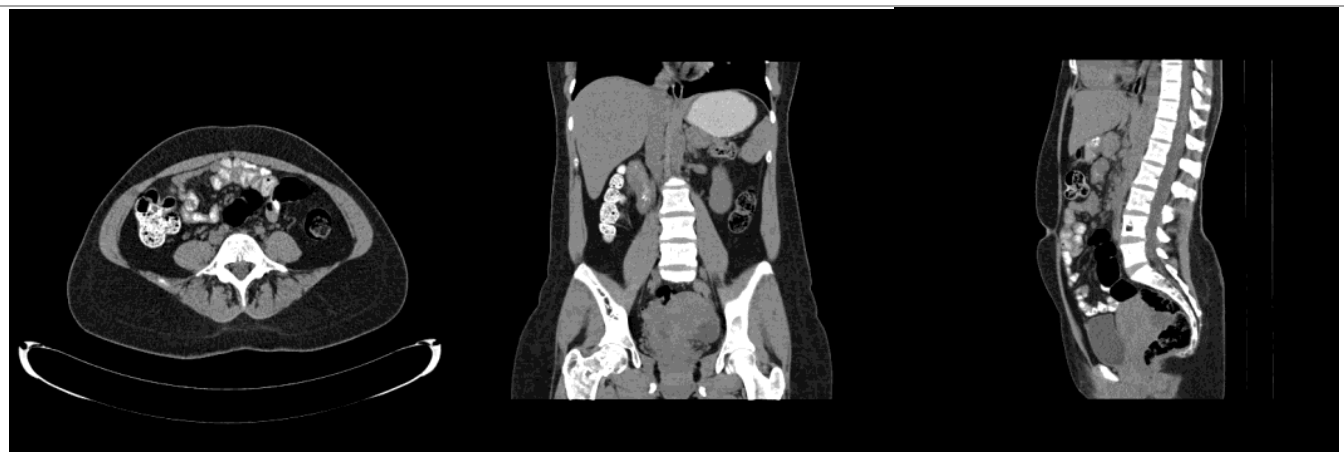

\section{Densitometria osea}

Riesgo de fractura: aumentado.

Diagnóstico: osteopenia

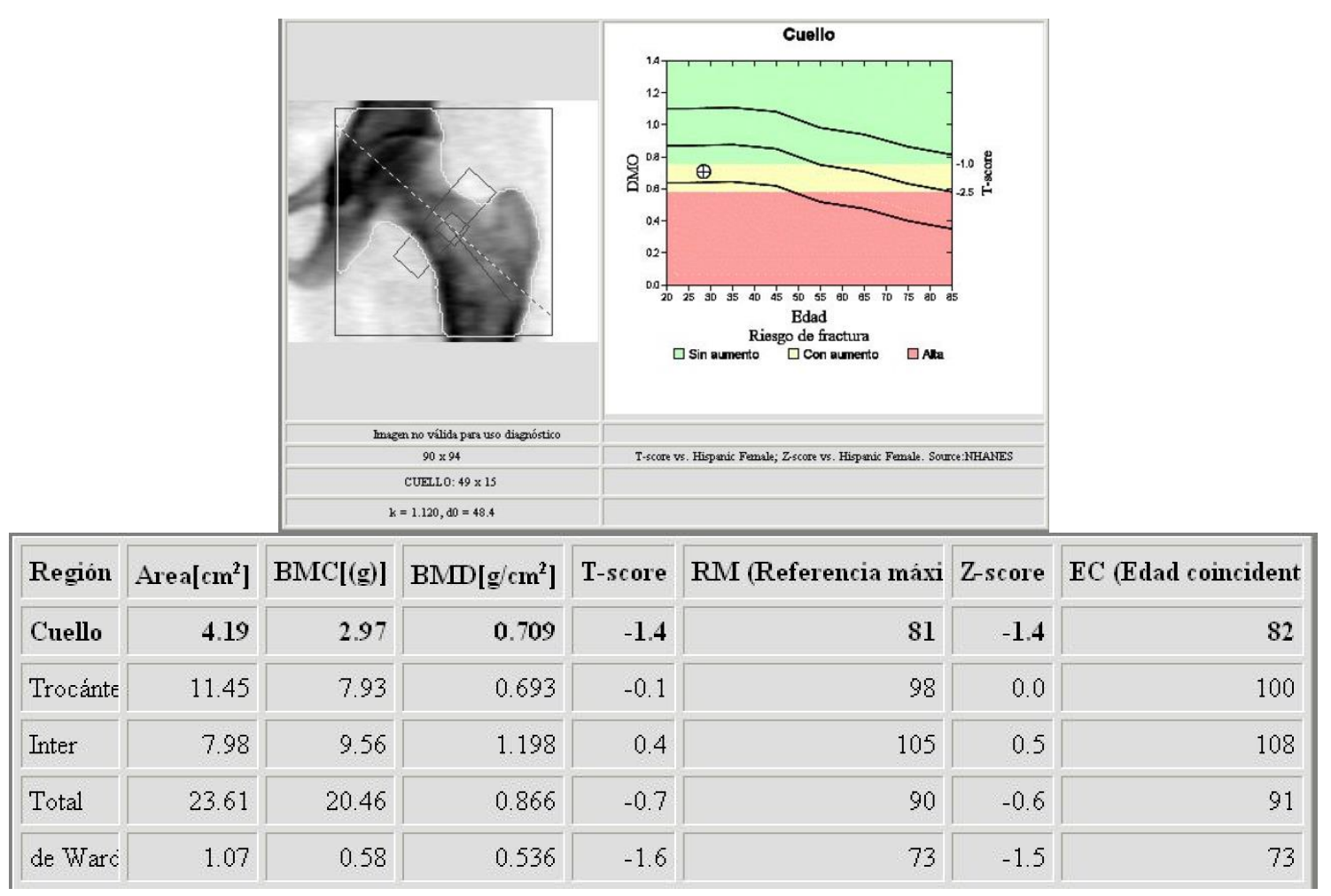




\section{Síndrome de McCune-Albright: multiples fracturas patologicas en paciente \\ con menarquia precoz}

Vol. 3, núm. 4., (2019)

Efrén Bryan Barco Ramírez; Verónica Ayling Lama Asínc; Jorge Andrés Carbo Palacio; Freddy

Leónidas Monge Paladines

\section{Biopsia puncion}

Tejido de muestra: medula osea de cresta iliaca.

Diagnóstico: medula ósea normocelular con maduracion normoblastica.

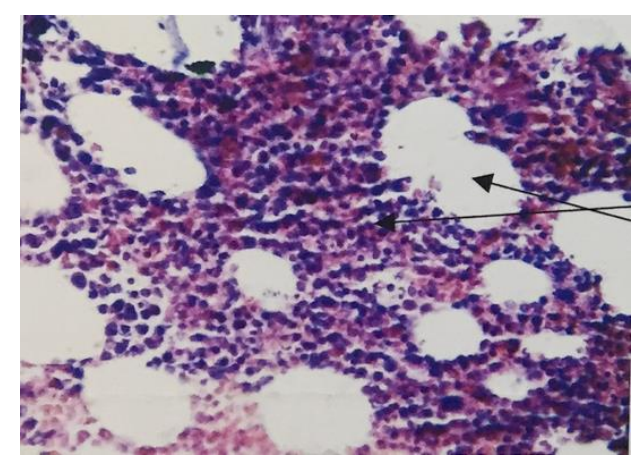

Paciente es diagnosticada con el síndrome de MCcune Albright.

\section{Discusión.}

En el pasado, la descripción completa del síndrome de McCune Albright (SMA) se realizó de forma separada por los colaboradores de Donovan McCune y Fuller Albright, a pesar de que previamente se reportaron casos parecidos. En el año 1936, D. McCune relató el caso de una niña con pigmentación cutánea con manchas café con leche, displasia fibrosa poliostótica, pubertad precoz e hipertiroidismo. Al año siguiente F. Albright reunió 5 casos femeninos similares, por lo cual en 1937 se logró obtener información más completa de esta entidad que tomo el nombre de sus descubridores. (1) (2) (3)

El síndrome de McCune-Albright constituye una entidad poco común que asocia la tríada compuesta por displasia fibrosa poliostótica, pigmentación de la piel bajo la forma de manchas 


\section{Síndrome de McCune-Albright: multiples fracturas patologicas en paciente con menarquia precoz}

Vol. 3, núm. 4., (2019)

Efrén Bryan Barco Ramírez; Verónica Ayling Lama Asínc; Jorge Andrés Carbo Palacio; Freddy Leónidas Monge Paladines

café con leche y pubertad precoz, sin embargo, se ha reconocido que otras endocrinopatías, incluidos el hipertiroidismo, el exceso de hormona de crecimiento $(\mathrm{GH})$, la pérdida renal de fosfato con o sin raquitismo / osteomalacia y el síndrome de Cushing podrían encontrarse en asociación con la tríada original. La forma no clásica del SMA consta de solo dos de los tres componentes de la triada clásica. En raras ocasiones, otros órganos pueden estar involucrados (hígado, corazón, paratiroides, páncreas). La incidencia mundial del SMA es desconocida, pero se estima una frecuencia de 1 caso por cien mil a 1 caso por millón.

En el año 2012 en un estudio realizado en dos hospitales del Centro Medico Nacional Siglo XXI en Mexico D.F se valoro a 12 pacientes de entre 19 meses a 29 años de edad que presentaron displasia fibrotica poliostotica, manchas café con leche y alteraciones endocrinas, siendo así una enfermedad poco común que se presenta con poca frecuencia, debutando en la infancia y afectando a ambos sexos, sin embargo, por razones desconocidas posee un claro predominio por la población femenina (relación mujer/ varón de 10 a 1), no posee una predilección por una raza o etnia específica. (2) (4) (5) (6) (7) (8)

La expresión clínica depende de la cantidad de células mutadas y órganos afectados. Por lo tanto, la presentación puede ser heterogéneo, que implica varios órganos endocrinos y no endocrinos. Puede ser de inicio temprano o tardío con evolución lenta o rápida. Esta anormalidad conduce a la proliferación de células osteoprogenitoras indiferenciadas, por lo tanto, hay aumento de la matriz fibrosa con tejido oseo. La presentación clínica de SMA es altamente variable, dependiendo de cuál de los componentes del síndrome predomina. La forma clásica de SMA es más común en las mujeres y está definida por la tríada compuesta por displasia fibrosa 


\section{Síndrome de McCune-Albright: multiples fracturas patologicas en paciente con menarquia precoz}

Vol. 3, núm. 4., (2019)

Efrén Bryan Barco Ramírez; Verónica Ayling Lama Asínc; Jorge Andrés Carbo Palacio; Freddy

Leónidas Monge Paladines

poliostótica, endocrinopatía e hiperpigmentación de la piel, pero para instaurar el diagnóstico es aceptable la asociación de 2 de los 3 hallazgos que componen la tríada clásica, ya que en la mayoría de casos es un síndrome evolutivo. Por lo general, los signos y síntomas de pubertad precoz o displasia fibrosa ósea debutan como presentación inicial, mientras que la pigmentación cutánea puede presentarse a nacer o poco después. La pubertad precoz puede manifestarse como sangrado vaginal en las niñas o agrandamiento testicular en los niños. Otros síndromes endocrinos pueden estar presentes, incluyendo hipertiroidismo, acromegalia y síndrome de Cushing. El síndrome de Mazabraud, que también puede existir en asociación con SMA e implica la aparición de mixomas y, por lo general, displasia fibrosa poliostótica (9) (7) (10)

El trastorno es el resultado de un trastorno postzigótico que consiste en una mutación somática en el gen GNAS 1 en el locus 20q 13.1-13.2, que codifica la subunidad alfa de la proteína $\mathrm{G}$ estimulante (Gsa). Las proteínas $\mathrm{G}$ acoplan los receptores de superficie celular a proteínas intracelulares para activar o inactivar cascadas de señalización. La proteína G estimuladora normalmente se activa cuando una hormona $u$ otro ligando se une al receptor de superficie de la célula. La subunidad Gsa activada posteriormente se disocia del receptor, se une a la adenililciclasa y estimula un aumento en los niveles de adenosin monofostato cíclico intracelular (cAMP) y posteriomente existe falla en la diferenciación del osteoblasto, y que vincula a un incremento en la resorción ósea por parte los osteoclasto, este último proceso es inducido por IL-6; a la vez el incremento celular del AMPc a nivel de los melanocitos en los cuales está presente la mutación estimula la actividad de la tirosinasa, lo que hace que exista una sobreproducción de melanina. La subunidad Gsa se inactiva, se vuelve a asociar con el 


\section{Síndrome de McCune-Albright: multiples fracturas patologicas en paciente con menarquia precoz}

Vol. 3, núm. 4., (2019)

Efrén Bryan Barco Ramírez; Verónica Ayling Lama Asínc; Jorge Andrés Carbo Palacio; Freddy Leónidas Monge Paladines

receptor y vuelve a ser disponible para reactivarse por medio de hormonas. Dado que el SMA resulta de una mutación somática postzigótica y existe un mosaicismo genético, todas las células hijas de la célula embrionaria en la que se produjo la mutación inicial también contienen la mutación. Cuanto antes se produce la mutación en la embriogénesis, más extendida está la afectación del tejido. Las mutaciones tardías en la embriogénesis están más enfocadas y explican los casos leves en los que solo están presentes 2 o 3 de las características fenotípicas clásicas del síndrome. Si la mutación ocurre muy tarde en el desarrollo del tejido después de la diferenciación en una línea celular específica, entonces puede producirse un solo adenoma. Se han informado mutaciones Gs alfa-activadoras en nódulos tiroideos hiperfuncionantes aislados y en adenomas somatotropos (2) (11) (4) (9)

La displasia fibrosa generalmente se presenta en la infancia o adolescencia temprana. La presentación más común son manifestaciones que incluyen dolores óseos, alteración en la marcha, rigidez de las articulaciones con dolor, deformidades oseas visibles y fracturas patológicas. Puede afectar a un solo hueso denominándose displasia fibrosa monostótica o numerosos huesos denominándose displasia fibrosa poliostótica. Aproximadamente el 70-80\% de los casos posee una presentacion monostótica y el 20-30 \% son poliostóticos. En el esqueleto apendicular por lo general se presenta con cojera y / o dolor, muchas veces los niños lo refieren como cansancio, en ocasiones una fractura patológica puede ocurrir como debut, cuando la displasia fibrosa ocurre en los huesos craneofaciales generalmente se presenta como un "bulto" indoloro o asimetría facial, sin embargo, las áreas más comúnmente involucrados son el fémur proximal y base del cráneo. (11) (5) (12) 


\section{Síndrome de McCune-Albright: multiples fracturas patologicas en paciente \\ con menarquia precoz}

Vol. 3, núm. 4., (2019)

Efrén Bryan Barco Ramírez; Verónica Ayling Lama Asínc; Jorge Andrés Carbo Palacio; Freddy

Leónidas Monge Paladines

La hiperpigmentación cutánea consiste en manchas que van desde el marrón claro hasta

el marrón oscuro, que a menudo muestran una distribución segmentaria, y con frecuencia predominan en un lado del cuerpo, pueden cruzar la línea media, pero más a menudo, respeta la línea media. Los lugares frecuentes son la nuca del cuello y el pliegue en el ápice de las nalgas. En retrospectiva, puntos de café con leche generalmente están presentes al nacer o bien se presentan poco después. Como tal, pueden ser una pista temprana para el diagnóstico. Se han descrito clásicamente como que tienen una frontera de "costa de Maine", que se refiere a la apariencia irregular de la costa de Maine como aparece en los mapas, sin embargo, esto no siempre se cumple. (2) (5) (7)

La pubertad precoz independiente de los niveles de gonadotropinas usualmente se manifiesta en las niñas con sangrado o manchado vaginal, acompañado por desarrollo de tejido mamario, generalmente sin desarrollo de vello púbico. Se observan formas de precocidad sexual en más del 50\% de las mujeres con SMA. En los niños, puede presentarse con un agradamiento testicular bilateral o unilateral con agrandamiento del pene, rugosidad escrotal, olor corporal, vello púbico y axilar sumado a un comportamiento sexual precoz. (2) (5) (7)

El hipertiroidismo es poco frecuente sin otras características del SMA también presentes, los hallazgos pueden incluir taquicardia, arritmias, principalmente supra ventriculares, hipertensión, hipertermia, temblor, insomnio, pérdida de peso o retraso en el desarrollo en lactantes. Otras posibles manifestaciones que pueden coexistir incluyen al síndrome de Cushing, Exceso de hormona del crecimiento manifestado como gigantismo y acromegalia, tumores de tiroides, tumores pituitarios, hipofosfatemia manifestado como raquitismo hipofosfatémico, 


\section{Síndrome de McCune-Albright: multiples fracturas patologicas en paciente con menarquia precoz}

Vol. 3, núm. 4., (2019)

Efrén Bryan Barco Ramírez; Verónica Ayling Lama Asínc; Jorge Andrés Carbo Palacio; Freddy Leónidas Monge Paladines

hipogonadismo hipogonadotrópico, particularmente en el contexto de hiperprolactinemia y quistes en los ovarios (2) (11)

El SMA se puede confundir con la neurofibromatosis generalmente cuando un niño presenta manchas cafés con leche. La ubicación y la forma de los puntos generalmente pueden ayudar a distinguir el SMA de la neurofibromatosis, ya que la hiperpigmentación de SMA tiene bordes dentados, mientras que la hiperpigmentación de la neurofibromatosis tiene bordes suaves, pero se debe considerar un diagnóstico de neurofibromatosis si se observa un historial familiar de pigmentación de café con leche. En el SMA, la enfermedad esquelética casi siempre implica uno o ambos fémures proximales y / o el cráneo base, así como otros lugares, mientras que la implicación esquelética en la neurofibromatosis es poco común y generalmente involucra las diáfisis de los huesos largos, especialmente las tibias, a menudo conducen a pseudoartrosis. Cuando la pubertad precoz es el signo que se presenta en primera instancia, el diagnóstico diferencial incluye neoplasia ovárica y pubertad precoz central, las pacientes con hemorragia vaginal precoz o desarrollo mamario, se deben considerar otras posibles causas de exceso de estrógenos. La ingestión accidental de suplementos de estrógenos puede causar desarrollo de los senos, aumento de la velocidad de la altura y maduración del revestimiento endometrial. A medida que los niveles de estrógeno disminuyen, puede producirse un sangrado por deprivación Si se produce sangrado vaginal en ausencia de otros signos de exceso de estrógenos como el desarrollo de los senos o aumento de la velocidad de crecimiento, se debe obtener una historia cuidadosa teniendo en cuenta posibles traumas o abusos sexuales. La Displasia osteofibrosa se puede confundir con la displasia fibrosa del SMA, las lesiones de la displasia osteofibrosa se 


\section{Síndrome de McCune-Albright: multiples fracturas patologicas en paciente \\ con menarquia precoz}

Vol. 3, núm. 4., (2019)

Efrén Bryan Barco Ramírez; Verónica Ayling Lama Asínc; Jorge Andrés Carbo Palacio; Freddy

Leónidas Monge Paladines

suelen encontrar casi exclusivamente en la tibia y el peroné, y son histológicamente distintos de la Displasia fibrosa. Por otro lado, El fibroma no osificante puede compartir similitudes radiológicas es histológicas con la Displasia Fibrosa en los huesos largos. Es recomendable realizar un diagnóstico diferencial con diversas afecciones como: Displasia fibrosa monostótica, Neurofibromatosis, Síndrome de Cushing, Hipertiroidismo, Terapia con hormonas tiroideas, Terapia con glucocorticoides, Pubertad precoz de tipo central, Gigantismo y acromegalia, Tumor funcionante de ovario, Raquitismo hipofosfatémico, , Síndrome de Proteus, Síndrome de Mazabraud y Enfermedad de Paget. (2)

Se debe realizar estudios endocrinos completos, los estudios de laboratorio que pueden ser útiles incluyen los siguientes: Determinación de los niveles de Gonadotropinas y niveles de hormonas sexuales, biometría hemática completa y química urinaria, prueba de tiroides midiendo los niveles la hormona estimulante de la tiroides (TSH), tiroxina (T 4), anticuerpos antitiroideos, Niveles de hormona adrenocorticotropa (ACTH), Prolactina sérica (PRL), Prueba de supresión con dexametasona (dosis estándar o baja / dosis alta), recolección de orina analizada para cortisol libre, niveles de la hormona del crecimiento $(\mathrm{GH})$ y del factor de crecimiento similar a la insulina 1 (IGF-1) y prueba de reacción en cadena de la polimerasa (PCR), niveles de calcio y fósforo séricos, Fosfatasa alcalina sérica, N-telopéptidos e hidroxiprolina urinarios, Osteocalcina sérica y enzimas hepáticas. Las modalidades de diagnóstico por imágenes que se pueden considerar incluyen las siguientes: Radiografía simple principalmente cráneo y mandíbula, es decir un examen craneofacial, pelvis, fémures, según lo indicado clínicamente, Ultrasonografía (cuello y tiroides, ovárico y pélvico, según lo indicado clínicamente ya que 


\section{Síndrome de McCune-Albright: multiples fracturas patologicas en paciente con menarquia precoz}

Vol. 3, núm. 4., (2019)

Efrén Bryan Barco Ramírez; Verónica Ayling Lama Asínc; Jorge Andrés Carbo Palacio; Freddy Leónidas Monge Paladines

permite detectar y medir quistes de ovarios, Tomografía computarizada (TC) que puede ser útil para detectar hiperplasia suprarrenal y atrapamiento de nervios intracraneales, Resonancia magnética (MRI); como clínicamente pertinente Escaneo de radionucleidos óseos (11) (5) (3) (8)

Con respecto a la histología, las areas afectadas por la displasia fibrosa se componen por gran cantidad de células parecidas a los fibroblastos con mínima matriz extracelular, abundancia de células proosteogénicas que maduran en osteoblastos anormales. Existe un patrón óseo con aspecto desorganizado, semejante a una "sopa alfabética" o de "letras chinas", el osteoide es de forma irregular (retorcido) con un estroma fibroso muy celular. (2)

No existe un tratamiento específico para el SMA. Los agentes farmacológicos que se han usado para tratar la pubertad precoz en SMA incluyen los siguientes Inhibidores de aromatasa, Análogos de la hormona liberadora de gonadotropina, Ketoconazol, Agonistas del receptor de estrógeno como el tamoxifeno, Espironolactona, Acetato de ciproterona, Acetato de medroxiprogesterona. Actualmente, no hay terapias médicas clínicamente probadas disponibles para la displasia osteofibrosa poliostotica asociados con SMA. Los bisfosfonatos orales e intravenosos como el Pamidronato, alendronato, zoledronato, ayudan a aliviar el dolor y pueden ser beneficiosos para prevenir la progresión de la enfermedad, aunque los datos son contradictorios. Los agentes farmacológicos que se han usado para tratar el hipertiroidismo en MAS incluyen los siguientes Tionamidas como el Propiltiouracilo, Metimazol, Radioyodo para la ablación de tejidos. No hay disponible un tratamiento médico efectivo a largo plazo para el síndrome de Cushing independiente de ACTH. Los agentes farmacológicos que se han usado 


\section{Síndrome de McCune-Albright: multiples fracturas patologicas en paciente con menarquia precoz}

Vol. 3, núm. 4., (2019)

Efrén Bryan Barco Ramírez; Verónica Ayling Lama Asínc; Jorge Andrés Carbo Palacio; Freddy

Leónidas Monge Paladines

para tratar el exceso de GH en SMA incluyen al octreotide, agonistas de la dopamina como la

Bromocriptina y la cabergolina, generalmente junto con octreotida, antagonistas del receptor de GH como el Pegvisomant probablemente no se usen mejor como monoterapia en este entorno. (11) (4) (8)

El tratamiento farmacológico de otras manifestaciones de SMA es el siguiente:

- Hipogonadismo: terapia de reemplazo hormonal apropiada

- Hipofosfatemia con hiperfosfaturia: reemplazo agresivo de fósforo oral

- Raquitismo hipofosfatémico - Terapia apropiada de calcitriol con la reposición de calcio y fosfato

- Las intervenciones quirúrgicas que se pueden considerar incluyen las siguientes:

- Pubertad precoz: ooforectomía o cistectomía ovárica, cuando falla el tratamiento médico

- Displasia fibrosa poliostotica: tracción o fijación para fracturas; para la mayoría de las lesiones. No se justifica la remoción rutinaria de la displasia fibrosa poliostotica

- Hipertiroidismo: tiroidectomía parcial, casi total o total

- Síndrome de Cushing Infantil - Adrenalectomía bilateral 


\section{Síndrome de McCune-Albright: multiples fracturas patologicas en paciente con menarquia precoz}

Vol. 3, núm. 4., (2019)

Efrén Bryan Barco Ramírez; Verónica Ayling Lama Asínc; Jorge Andrés Carbo Palacio; Freddy Leónidas Monge Paladines

Gigantismo o acromegalia: la extirpación quirúrgica de la lesión central rara vez es curativa y solo se considera si el tumor amenaza la visión en consulta previa con un neurocirujano experimentado en base de cráneo (5) (7) (8)

Con respecto a la expectativa de vida de los pacientes con SMA, este es relativamente normal, ya que no se asocia a un aumento significativo en la mortalidad, sin embargo el pronóstico y las complicaciones pueden variar dependiendo de las manifestaciones del SMA; la displasia fibrosa puede tener efectos graves, que incluyen fracturas patológicas, desfiguración facial y problemas de visión y audición. Las terapias actuales se enfocan en el tratamiento de las complicaciones de la displasia fibrosa, en lugar de evitar que se desarrolle. Los estudios actuales que usan bisfosfonatos son prometedores, aunque no está claro si los bisfosfonatos reducen significativamente la morbilidad asociada con estas lesiones. La pubertad temprana no es una afección potencialmente mortal y no parece conducir a problemas clínicos posteriores. Es posible que existan complicaciones debido a manifestaciones endocrinológicas que se puede asociar al SMA así, el hipertiroidismo puede ocasionar alteraciones del desarrollo en la infancia y osteoporosis la taquicardia resultante de un hipertiroidismo severo puede complicar o desencadenar un evento cardíaco; si se asocia un síndrome de Cushing infantil puede causar una falla grave de crecimiento, tono muscular deficiente e hipertensión. (13) (8)

\section{Bibliografía.}

1. Garcés J, Munduteguy M, Romero C. Síndrome de McCune-Albrigth Evaluación del Compromiso Craneofacial y de Columna por Imágenes de Resonancia Magnética. Neurorradiología Caso clínico. 2011 Enero; 75(1).

2. Riverón DLOM. Enfermedad de McCune-Albright. Revista Cubana de Ortopedia y 


\section{Síndrome de McCune-Albright: multiples fracturas patologicas en paciente \\ con menarquia precoz}

Vol. 3, núm. 4., (2019)

Efrén Bryan Barco Ramírez; Verónica Ayling Lama Asínc; Jorge Andrés Carbo Palacio; Freddy

Leónidas Monge Paladines

Traumatología. 2005 Junio.

3. POMA A. Síndrome de McCune-Albright: Evaluación del Compromiso Craneofacial por Imágenes de Resonancia Magnética. Anales de la Facultad de Medicina Universidad Nacional Mayor de San Marcos. 1999; 60(3).

4. Ballesteros S. SÍNDROME DE McCUNE-ALBRIGHT: REPORTE DE CASO Y REVISIÓN DE LA LITERATURA. Rev.Medica.Sanitas. 2015 Octubre; 18(4).

5. Collins C, Dumitrescu E, Michael T. McCune-Albright syndrome. Orphanet Journal of Rare Diseases. 2008 May; 3(12).

6. HAPPLE R. The McCune-Albright syndrome: a lethal gene surviving by mosaicism. Clinical Genetics. 1986; 29.

7. Hernández L, Espinosa M, Méndez V. Síndrome de McCune-Albright: características clínicas en una población pediátrica y adulta. Revista de Endocrinología y Nutrición. 2012 Enero; 20(1).

8. Gabriel I, Uwaif M. Medscape. [Online].; 2017 [cited 2017 April 26. Available from: https://emedicine.medscape.com/article/127233-overview.

9. Pitarch Bort G, Laguna Argente C, Martín González B. Síndrome de McCune-Albright. Casos clinicos Servicio de Dermatología. Hospital General Universitari de València. 2009; 37(3).

10. Martínez-Hervás S ea. Síndrome de McCune-Albright: otra forma de neoplasias endócrinas múltiples. Notas clínicas Servicio de Endocrinología y Nutrición. Hospital Clínico Universitario de Valencia Departamento de Medicina. 2005; 52(4).

11. Bhadada SK. Fibrous dysplasia \& McCune-Albright syndrome: An experience from a tertiary care centre in north India. INDIAN J MED RES. 2011 May.

12. Sabatel Hernández G ea. Displasia ósea fibrosa en el contexto de un síndrome de McCuneAlbright. Notas clinicas. 2004; 23(3).

13. Garibaldi L, Chemaitilly W. A.D.A.M Multimedia Encyclopedia. [Online].; 2016 [cited 2016 August

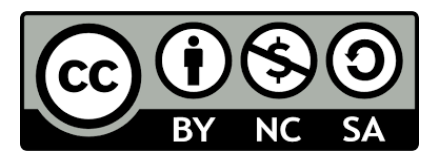

RECONOCIMIENTO-NOCOMERCIAL-COMPARTIRIGUAL

CC BY-NC-SA

ESTA LICENCIA PERMITE A OTROS ENTREMEZCLAR, AJUSTAR Y CONSTRUIR A PARTIR DE SU OBRA CON FINES NO COMERCIALES, SIEMPRE Y CUANDO LE RECONOZCAN LA AUTORÍA Y SUS NUEVAS CREACIONES ESTÉN BAJO UNA LICENCIA CON LOS MISMOS TÉRMINOS. 